\title{
Extraperitoneal (RT) Renal Ectopia - Asymptomatic Case Report
}

\author{
Afodun Adam Moyosore ${ }^{1,2}$, Edgar Mario Fernandez ${ }^{1}$, Buhari Muhammad Olanrewaju', Okesina Akeem Ayodeji ${ }^{1}$, Quadri \\ Khadijah Kofoworola ${ }^{3}$, Ogbe Alex ${ }^{1}$ \\ ${ }^{1}$ Senior Lecturer, Department of Anatomy, School of Biomedical Sciences, Kampala International University, Western Campus, Ishaka, Uganda, \\ ${ }^{2}$ Consultant Ultrasonologist, Department of Radiology, Ultrasound and Doppler Unit, Crystal Specialist Hospital, Akowonjo-Dopemu, Lagos, ${ }^{3}$ Department of \\ Physiology, College of Medicine, University of Lagos.
}

\section{Abstract}

Renal ectopia anatomically results from altered migration of kidneys to their normal position in the lumbar region. Few case reports have been reported in literature. Visceral-tissue variation was in form of quadratus lumborum and psoas major in place of the RT kidney. A 21 year old female with positive HCG (pregnancy test) presented for radiological (ultrasound) confirmation of cyesis, though no sonic evidence of gravidae was observed ( $<5$ wks GA); confirmatory ectopic kidney was diagnosed on completion of ultrasound. This report underscores the importance of imaging the RT groin and illiac region before surgical intervention thus preventing iatrogenic injury genesis. Treatment of this condition will depend on the functional capacity of the kidney, while nephrectomy is recommended for 'static' nonfunctional kidneys. Non-complicated cases and anatomic variation can be managed conservatively.

Keywords: Cyesis, gravidae, ultrasound, gestational age.

Corresponding Author: Dr. Afodun Adam Moyosore, Senior Lecturer, Department of Anatomy, School of Biomedical Sciences, Kampala International University, Western Campus, Ishaka, Uganda.

Received: May 2018

Accepted: July 2018

\section{Introduction}

The fetal kidneys during early development first appear as buds inside the pelvis which later ascend to the lumbar region. It is reported that thoracic or renal ectopia may be congenital or acquired, rarely occurs bilaterally and occurrence is mostly in males with preponderance at the left lateral side. ${ }^{[1,2]}$ Sparse record of ectopic kidney as been reported in South-West Nigeria; Ilah et $\mathrm{al}^{[3]} 2015$ documented rare statistical prevalence. A paper by Tsao et al (2008) and Mokoema et al (1996) reported a complication of ectopic kidney and renal infection (Pyelonephritis). ${ }^{[4,5]}$ Although the current case is rare, there is paucity of literature on physical interaction of the uterus and a kidney. Anatomical variations in the urinary system occurs and may include differences in kidney shape, calyces-length, bladder - volume, urethra or (bilateral) ureters. Ectopic and 'pelvic' kidneys are due to embryological distortions in renal migration. ${ }^{[6,7]}$ This literature also emphasis the importance of imaging the pelvic region prior to surgical interventions such as appendectomy or hernioraphy. Several factors such as genetic, teratogenic and maternal diseases during nephrogenesis interfere with normal kidney development. ${ }^{[8]}$ Though some types of ectopic kidneys are functional, cases of kidney arterio-venous fistulae have been reported in relation to pelvic kidney. The fetal kidneys during early development first appear as buds inside the pelvis which later ascend to the lumbar region. ${ }^{[6]}$

Renal pelvic kidney can occur on either side, female to male gender variation has been reported. ${ }^{[9]}$ As in this case (asymptomatic) ectopic kidney may be symptomatic in other occurrence. ${ }^{[10]}$ Urologist intervention and nephrectomy are needed in symptomatic complicated cases, (stones/calculi, infection or edema) which could arise; and later managed conservatively.

\section{Case Report}

A 21 year old female patient presented for ultrasound (cyesis confirmation) at Crystal Specialist Hospital, DopemuAkowonjo, Lagos, Nigeria. She was in (apparent) good health and had no history of dysuria, frequency, menstrual fluctuation or acute pelvic pain. Pelvic ultrasound scan revealed no decidua-cyetic echogenicity; though with a strongly positive beta-HCG (assumed to be $<5$ wks GA) RT renal ectopia was clearly demonstrated with pedunculatedcontact with the right extra-fundal region.

On examination (through palpitation) our patient was interactive and alert with a non-distended abdomen. Rebound tenderness was noticed on probe contact in the Right Lower Quadrant (RLQ) with perceived 'heaviness' 
felt by the subject. Verbal questioning of patient and observation showed no transient or intermittent evidence of cyanosis. Her obstetric course thus far had been uncomplicated. The sonar equipment used was a General Electric (GE) Logic 3 Pro, Ultrasound System (made in the USA) with a $3.5 \mathrm{MHz}$ transducer. Patient consent was sought and ethical approval was granted by CSH in line with the 1975 Helsinki Declaration on patient rights' and confidentiality. Medical counselling was provided to the patient afterwards on the dangers of iliac/pelvic compression and unrelated surgical procedure by an unwary surgeon. No referral for nephrectomy was given and urine culture from renal ectopia showed no evidence of bacterial growth.

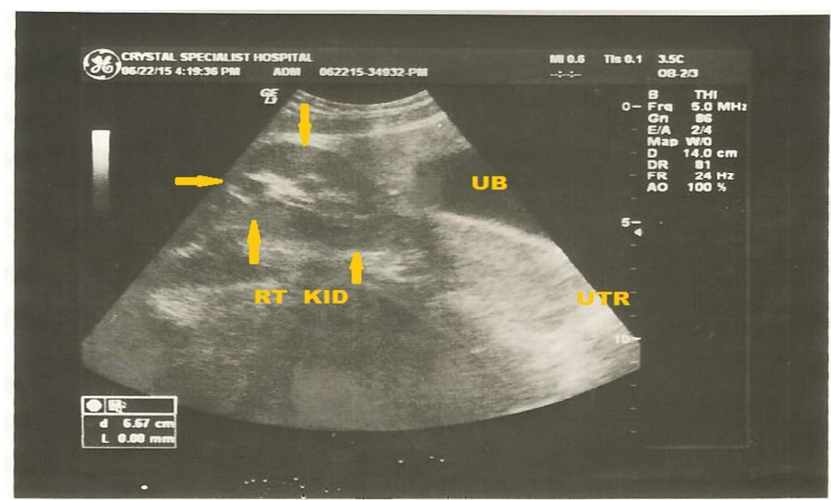

Figure 1: Longitudinal view right ectopic kidney (arrowed) resting in the illiac fossa with pedunculated fundal attachment to the upper uterine (UTR) surface. Note the anechoic urinary bladder (UB).

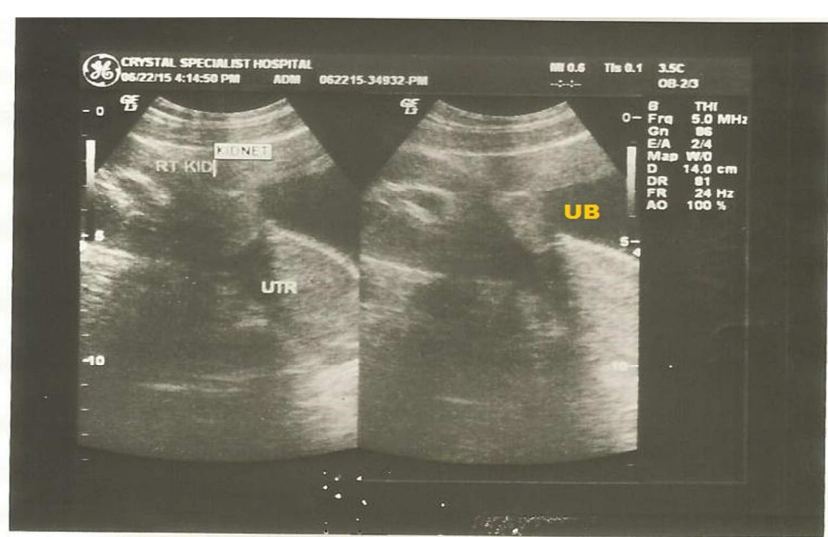

Figure 2: LS of the same renal ectopia (RT KID), Split sonogram of B-mode in relation to the urinary bladder (UB). Note the echogenic central medulla and uterus labelled UTR.

\section{Discussion}

In 2008, Asghar and Wasir ${ }^{[18]}$ reported the prevalence of ectopic kidneys in patients with abdominal swelling and protrusion. Symptoms of urinary discomfort and lower abdominal pain (symptomatic) was reported by others ${ }^{[11]}$ concerning ectopic kidneys [Figure 1]. Individuals with renal ectopia usually have incidents of increased urinogenital anomalies ${ }^{[14]}$, cryptorchidism or urethral duplications can be seen in males. Most ectopic kidneys are non-malignant and the other kidney is mostly normal. Ectopic kidneys may be pelvic, abdominal or illiac or anywhere along the path of their crossed ascent. ${ }^{[12]}$

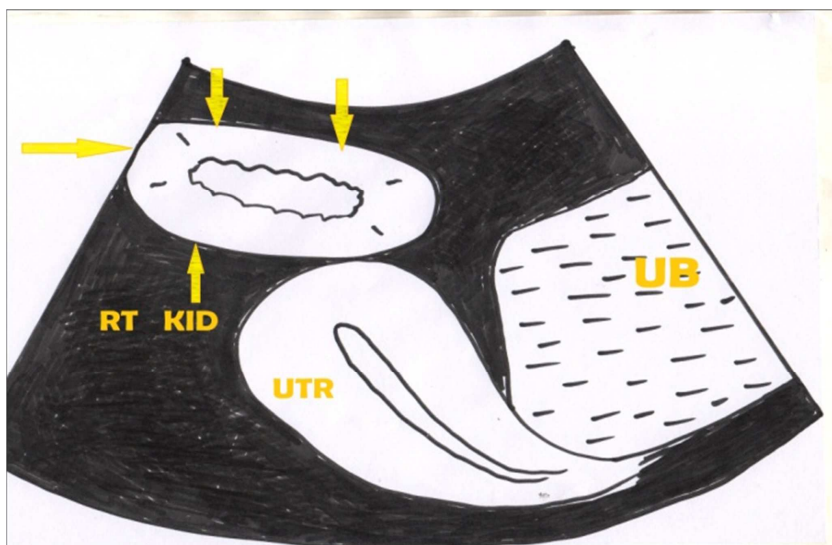

Figure 3: Schematic diagram representing Figure 1 above, pelvic kidney in relation to bladder (UB) and uterus (UTR).

As stated, others ${ }^{[13]}$ noted some complications with the pelvic kidney. The collecting-system of kidneys in most ectopic cases are dilated and hydronephrosis may occur due to malrotation but are mostly asymptomatic. Complications could occur from infection (in extraperitoneal region) or obstruction. Low incidence of pelvic kidneys necessitates regular, safe and non-invasive ultrasound for (coincidental) diagnosis as the case may be. Ectopic kidney has a reported frequency of 1:500 to 1:1100; single kidney 1:1000; solitary pelvic kidney 1: 22000; thoracic-ectopic kidney 1: 13000; pelvic kidney 1:3000, and contralateral (crossed) renal ectopia [Figure 2]. ${ }^{[14,15]}$ Bilateral renal ectopia in horse-shoeshape or form is rarely encountered. The medical danger of this case report is that it could be misdiagnosed for acute appendicitis. Ascent of the kidney precedes descent of gonadal bulbs which reach the pelvic brim around 27 weeks in-utero. As a consequence of RT renal ectopia [Figure 1 and 3], no evidence of hepatic depression was seen on sonar. For the same reason, the right ovary was found, proximal to the cul-de-sac (Douglas Pouch). Contrary to what was reported by Belsare et $\mathrm{al}^{[14]}$ (2002) in his indication of congenital pelvic kidney been commoner on the left side than the right. He also stated higher frequency in males than females, contrary to our case where it was found in a female patient. Our case-report is in line with what Kemper and Müller 2001; ${ }^{[16]}$ and Rascher's et al (2005) observed. ${ }^{[17]}$ Factors that may obstruct embryologic renal movement include defective metanephric tissue, teratogenic factors and mal-development of ureteral bud.

Sonogram study presumes that under-ascent is more common than kidney over-ascent; making ectopic kidneysmore commonly located in the lower abdomen and supra-pelvic region.Also, ectopic kidneys may result in dermatomal referred pain or pelvic inflammatory disease (in women); thus a typical potential for misdiagnosis is always present. This present case [Figures 1,2 and 3] was free of right kidney anomaly and reproductive malformation, however vasculature in renal ectopia can vary and be tortuous, others reported more than one aberrant artery originating from external illiac artery, ${ }^{[17]}$ abdominal aorta or common illiac artery. In future cases before any form of medical intervention,complimentary color Doppler scan is suggested to further evaluate the course of the renal artery and veins. 


\section{Apadun et al; Extraperitaneal Renal Ectapia}

\section{References}

1. Sfaxi M, Miladi M, Loussaief H, Munif A, Chebil M, Ayed M. Thoracic ectopic kidney by diaphragmatic herniation. Progres en Urologie 2002; 12: 447-78.

2. Lozano R, Rodriguez C. Intrathoracic ectopic kidney: report of a case. J Urol 1975; 114:601-2.

3. Ilah BG, Sakajiki AM, Aghadueki S, et al (2015) Ectopic pelvic kidney in a neonate in Gusau, Zamfara, North Western Nigeria. Sahel Medical Journal 2015; 18: 89 - 90.

4. Tsao YT, Lin SH, Lin YF, and Chu P. "Pelvic ectopic kidney with acute pyelonephitis: Wolf in sheep's clothing" American Journal of Emergency Medicine, Vol. 26, No. 4, pp.517 e3-517 e4, 2008.

5. Mokoena T, Nair R and Degiannis E. "Ectopic kidney presenting as appendix mass or abscess" South African Journal of Surgery Vol. 34, Nos 3, pp 142 - 143, 1996

6. Moore KL, Persuad TVN. The Developing Human, Clinically Oriented Embryology. 8th ed. Philadelphia WB Saunders 2008:244 56

7. Walsh P, Gittes R, Perimutter A. Cambell's Urology. Edition Philadelphia WB Saunders, 1986 1674-5.

8. Sashi K, Srinivasa RB, Venkata RV. Unilateral ectopic kidney in the pelvis - A case Report (2011) Chang Gung Med J 2011; 34 (6; suppl): $10-2)$.

9. Muthiah M, Arun K, Bilo D, Adithys M. A case series study of ectopic kidneys. Indian J Med Case Rep 2013; 2:52 - 6.

10. Lusch A, Koen M, Becker T, Engelhardt PF, Riccabona M. Pelvic kidney in childhood. Specific investigations, concomitant pathologies and useful diagnostic investigations. Urologe A. 2007; 46: 132 - 6.

11. Samaila IS, Shuaib KA. Case report: Ectopic kidney case report and contemporary literature review in North Eastern Nigeria BJW 2010; 12:2042 - 997

12. Baner SB. Anomalies of the kidney and ureteropelvic junction. In: Walsh PC. Retik AB, Vaughan ED, Jr, eds. Campbell's urology. 7th edition Philadelphia: WB Saunders, 1998; 1709 - 55.

13. Gleason PE. Hydronephrosis in Renal Ectopia: Incidence, Etiology and Significance. J Urol 151 (6), 1660-1661.

14. Belsare SM, Chimmaigi, Vaidya SA, Sant SM (2002) Ectopic kidney and associated anomalies: A case Report J Anat. Soc. India 51 (2) 236 - 238 (2002)

15. Bergman RA, Afifi AK and Miyauchi R In: Illustrated encyclopedia of human anatomic variation. Opus IV: Organ system urinary system: Kidneys, ureters, bladders and urethra@www/virtualhospital.com (2000).

16. Kemper MJ and Müller-Wiefel DE.(2001) Renal functions in congenital anomalies of the kidney and urinary tract. Curr Opin Urol. (Nov) 11 (6): 571-5.

17. Rascher W, Rosch W H. Cogenital abnormalities of the urinary tract Oxford Textbook of Clinical Nephrology. Oxford: Oxford University Press, Inc; 2005: 1402-12.

18. Asghar M, Wazir F. Prevalence of renal ectopia by diagnostic imaging. Gonal J Med Sci 2008; 62 - 5 .

19. Afodun A M, Bakare A A, Eze E D, Quadri K K (2017) Bilateral (Acute) Hydronephrosis Mimicking Polycystic Renal Pathology. MOJ Anat \& Physiol 4 (4): 00144.

Copyright: () the author(s), publisher. Academia Anatomica International is an Official Publication of "Society for Health Care \& Research Development". It is an open-access article distributed under the terms of the Creative Commons Attribution Non-Commercial License, which permits unrestricted non-commercial use, distribution, and reproduction in any medium, provided the original work is properly cited.

How to cite this article: Afodun AM, Edgar MF, Buhari MO, Okesina AA, Quadri KK, Ogbe A. Extraperitoneal (RT) Renal Ectopia Asymptomatic Case Report. Acad. Anat. Int. 2018;4(2):1-3.

DOI: dx.doi.org/10.21276/aanat.2018.4.2.1

Source of Support: Nil, Conflict of Interest: None declared. 